\title{
Analisis Defleksi Pada Rangka Alat Pembuat Briket Sampah Organik
}

\author{
Gregorius Agung Pamungkas $\mathrm{B}^{1)}$, IGN. Priambadi ${ }^{2)^{*}}$, AAIAS. Komaladewi ${ }^{3)}$ \\ 1)Jurusan Teknik Mesin Fakultas Teknik Universitas Udayana \\ Kampus Bukit Jimbaran, Bali 80362 \\ Email: Gregorius.budianto@gmail.com \\ ${ }^{2,3)}$ Program Studi Teknik Mesin Fakultas Teknik Universitas Udayana \\ Kampus Bukit Jimbaran, Bali 80362 \\ Email: priambadi.ngurah@unud.ac.id, komaladewijegeg@gmail.com
}

doi: https://doi.org/10.24843/METTEK.2020.v06.i02.p06

\begin{abstract}
Abstrak
Rangka merupakan bagian yang paling penting dari sebuah konstruksi dimana kekuatan rangka sangat ditentukan dari bentuk dan dimensi. Kekuatan rangka pada konstruksi harus memenuhi aspek keamanan serta harus memperhatikan faktor kekuatan rangka itu sendiri. Menghitung kekuatan rangka dari alat pembuat briket sampah organik dilakukan dengan menggunakan cara simulasi untuk mengetahui kekuatan rangka dalam menerima beban. Simulasi yang dilakukan dengan menggunakan software SolidWorks 19 dengan pembebanan statis, dan dengan variasi beban $110 \mathrm{~kg}$ dan $4500 \mathrm{~kg}$ dengan menggunakan material baja tipe ASTM A36. Proses simulasi yang telah dilakukan dengan pembebanan $110 \mathrm{~kg}$ nilai tegangan maksimum sebesar $6.66046 \mathrm{~N} / \mathrm{mm}^{2}$ (Mpa), nilai displacement maksimum sebesar $0.0114 \mathrm{~mm}$, nilai strain maksimum sebesar $0.0000167973 \mathrm{~mm}$, dan nilai safety factor minimal sebesar 38. Dengan pembebanan $4500 \mathrm{~kg}$ nilai tegangan maksimum sebesar $248.26596 \mathrm{~N} / \mathrm{mm}^{2}$ (Mpa), nilai displacement maksimum sebesar $0.4231 \mathrm{~mm}$, nilai strain maksimum sebesar $0.0006269075 \mathrm{~mm}$, dan nilai safety factor minimal sebesar 1. Pembebanan $110 \mathrm{~kg}$ rangka masih dapat menahan beban dan nilai stress masih jauh dari standar yield strength material ASTM A36 sebesar 250 Mpa. Terdapat perubahan bentuk rangka saat dilakukan pembebanan tetapi masih bersifat elastis, pada pembebanan $4500 \mathrm{~kg}$ rangka tidak dapat menahan beban dan nilai stress mendekati standar yield strength material ASTM A36 sebesar 250 Mpa. Hasil simulasi menunjukkan bahwa rangka alat pembuat briket sampah organik dengan beban $110 \mathrm{~kg}$ dan dengan material Baja tipe ASTM A36 mampu menahan beban dengan lebih baik. Dibandingkan dengan beban $4500 \mathrm{~kg}$ dan dengan material yang sama.
\end{abstract}

Kata kunci: Simulasi, Tegangan, Deformasi, dan Solidworks 2019

\begin{abstract}
The frame is the most important part of a construction where the strength of the frame is very much determined from the shape and dimensions. The strength of the frame in construction must fulfill the safety aspect and pay attention to the strength factor of the frame itself. Calculating the strength of the frame from the organic waste briquette maker is done by using a simulation method to see the strength of the frame in receiving the load. Simulations carried out using solidWorks 19 software with static loading with a load variation of $110 \mathrm{~kg}$ and $4500 \mathrm{~kg}$ using ASTM A36. The simulation process that has been carried out with a load of $110 \mathrm{~kg}$ with a maximum stress value of $6.66046 \mathrm{~N} / \mathrm{mm} 2$ (Mpa), a maximum displacement value of $0.0114 \mathrm{~mm}$, a maximum strain value of $0.0000167973 \mathrm{~mm}$, and a minimum safety factor value of 38 . At the
\end{abstract}

Penulis korespondensi,

Email: priambadi.ngurah@unud.ac.id 
load of $4500 \mathrm{~kg}$ the maximum stress value is $248.26596 \mathrm{~N} / \mathrm{mm} 2$ (Mpa), the maximum displacement value is $0.4231 \mathrm{~mm}$, the maximum strain value is $0.0006269075 \mathrm{~mm}$, and the safety factor value is at least 1 . A load of $110 \mathrm{~kg}$ the frame can still with stand the load and the stress value is still far from the standard yield strength material ASTM A36 of $250 \mathrm{Mpa}$. There is a change in the shape of the frame when it is charged but still elastic, at the load of $4500 \mathrm{~kg}$ the frame cannot with stand the load and the stress value is close to the standard yield strength material ASTM A36 of 250 Mpa. Simulation results showed that the frame of the organic waste briquette making tool with a load of $110 \mathrm{~kg}$ and with steel material type ASTM A36 is able to with stand the load better. Compared to a load of $4500 \mathrm{~kg}$ and with the same material.

Keywords: Simulation, Stress, Displacment, Solidworks 2019.

\section{PENDAHULUAN}

Dalam perencanaan pembuatan alat pembuat briket sampah organik, kekuatan rangka dalam menerima beban sangat berpengaruh pada hasil kinerja dari alat tersebut. Jika berat beban yang diterima rangka melebihi dari kemampuannya maka akan terjadi perubahan bentuk (Defleksi). Rangka berfungsi sebagai penyangga komponen, dan penguat struktur, model rangka yang dibuat terlebih dahulu kemudian disimulasikan. Simulasi dilakukan untuk mengetahui tegangan maksimum yang timbul akibat pembebanan statis pada rangka. Simulasi pada pemodelan bertujuan untuk mengetahui defleksi pada rangka alat pembuat briket sampah organik, hasil simulasi menunjukkan apakah hasil rancangan cukup kuat dan aman ketika alat tersebut diaplikasikan.

Dalam simulasi pada pemodelan ada beberapa permasalahan yang akan dikaji, yaitu:

1. Bagaimana kekuatan rangka ketika pembebanan dilakukan?

2. Bagaimana keamanan dari rangka ketika diberikan beban maksimal?

Sebagai batasan pada penelitian ini meliputi:

1. Rangka yang dianalisa dispesifikasikan untuk alat pembuat briket sampah organik

2. Tipe Baja yang digunakan dari material baja ASTM A36 dengan profil U.

3. Analisa dilakukan pada kekuatan maksimal rangka akibat proses pembebanan

4. Penelitian ini berfokus pada simulasi defleksi akibat pembebanan

5. Tidak menghitung beban dengan arah horizontal (sumbu X)

6. Perhitungan hanya pada beban statis

Rancangan konstruksi dari alat pembuat briket sampah organik ini terdiri dari rangkaian batang profil $U$ dengan menggunakan material baja ASTM A36. Rangkaian dari rangka disambung dengan sambungan las sehingga terbentuk rangka yang kaku dan mempunyai kekuatan serta keamanan saat diaplikasikan. Rancangan ini nantinya dibuatkan model untuk disimulasikan dengan memberikan beban statis ke arah gaya gravitasi sehingga dapat diketahui tegangan pada batang serta defleksi yang terjadi. Tegangan yang terjadi akibat pembebanan memberikan pengaruh pada batang sehingga timbul defleksi. Defleksi terjadi jika tegangan terjadi mencapai tegangan mulurnya dan deformasi yang terjadi bersifat permanen, maka itu merupakan beban maksimum yang dapat diterima rancangan dan hal ini menggambarkan keamanan rendah.

Baja karbon merupakan bentukan dari unsur besi dan karbon, yang mana karbon ini sebagai pengeras dari besi. Baja karbon banyak digunakan untuk material pada konstruksi baik bangunan atau kerangka untuk mesin. Material pada rancangan alat pembuat briket sampah organik ini menggunakan baja ASTM A36 yang mempunyai spesifikasi sebagai berikut : 
Tabel 1. Komposisi Baja ASTM A36

\begin{tabular}{|c|c|c|c|c|c|}
\hline \multirow{2}{*}{ Komposisi (\%) } & \multicolumn{5}{|c|}{ Tebal Pelat (mm) } \\
\cline { 2 - 6 } & $<20$ & $20-40$ & $40-65$ & $65-100$ & $>100$ \\
\hline Karbon (C), max & 0.25 & 0.25 & 0.26 & 0.27 & 0.29 \\
\hline Mangan (Mn) & & & $0.18-1.20$ & $0.08-1.20$ & $0.08-1.20$ \\
\hline Fosfor (P), max & 0.04 & 0.04 & 0.04 & 0.04 & 0.04 \\
\hline Suifur (S), max & 0.05 & 0.05 & 0.05 & 0.05 & 0.05 \\
\hline Sulcon (Si) & $0.04 \mathrm{max}$ & $0.04 \mathrm{max}$ & $0.15-0.40$ & $0.15-0.40$ & $0.15-0.40$ \\
\hline $\begin{array}{c}\text { Tembaga (Cu), } \\
\text { Jika ditentukan }\end{array}$ & 0.20 & 0.20 & 0.20 & 0.20 & 0.20 \\
\hline
\end{tabular}

Tabel 2.Standar Uji Tarik Baja ASTM A36

\begin{tabular}{|c|c|}
\hline $\begin{array}{c}\text { Tegangan Puncak } \\
\text { (Ultimate). [Mpa] }\end{array}$ & $400-500$ \\
\hline $\begin{array}{c}\text { Tegangan Luluh (Yield), } \\
\text { min, [Mpa] }\end{array}$ & 250 \\
\hline Regangan, min, \% & 23 \\
\hline
\end{tabular}

Tegangan merupakan kemampuan material menerima beban persatuan luas, dalam membuat suatu konstruksi maka langkah awal harus diketahui yaitu tegangan yang terjadi ketika diberikan pembebanan. Berdasarkan perhitungan tegangan yang terjadi pada konstruksi baru dilakukan pemilihan material yang cocok untuk digunakan. Tegangan material yang dipilih setidaknya harus lebih tinggi dari tegangan yang terjadi pada struktur tersebut, tegangan yang dimiliki oleh material yang dipilih ini disebut tegangan ijin. Tegangan ijin ini merupakan batas tegangan yang aman dan mampu diterima oleh konstruksi yang dirancang. Istilah dalam tegangan kerja dan tegangan kerja aman memberikan pengertian yang sama dan keduanya digunakan secara luas [1].

$$
\sigma=\frac{P}{A}
$$

Dimana :

$\sigma=$ tegangan yang terjadi $(\mathrm{N} / \mathrm{m} 2)$

$\mathrm{P}=$ beban yang diterima (Newton)

$\mathrm{A}=$ luas tampang $\left(\mathrm{m}^{2}\right)$

Defleksi merupakan perubahan bentuk dari konstruksi yang dirancang akibat pembebanan yang diberikan, perubahan yang terjadi bisa bersifat elastis maupun plastis. Sifatnya elastis terjadi maka konstruksi itu bisa kembali pada bentuk semula akan tetapi kalau sifatnya plastis konstruksi tidak kembali pada bentuk semula. Perubahan bentuk pada batang bisa dalam arah vertikal dan horizontal akibat adanya pembebanan yang diberikan pada balok atau batang [2]. Persamaan yang digunakan untuk mengetahui defleksi yang terjadi dapat dihitung persamaan berikut :

$$
\begin{aligned}
& \mathrm{EI} \cdot \frac{d^{2} y}{d x^{2}}=-\mathrm{Mx} \\
& \mathrm{I} \cdot \frac{d y}{d^{x}}=\mathrm{EI} \theta=\int M d x+\mathrm{C}_{1}(\text { Persamaan Kurva Kemiringan ) } \\
& \text { Eiy }=\iint M d x \cdot d x+\mathrm{C}_{1} \mathrm{x}+\mathrm{C}_{2} \text { (Persamaan Kurva Elastis ) }
\end{aligned}
$$


dimana :

$\mathrm{x}$ dan $\mathrm{y}=$ adalah sistem koordinat

$\mathrm{E} \quad=$ modulus elastisitas batang

I $\quad=$ momen inersia penampang batang terhadap sumbu netral.

$\mathrm{Mx} \quad=$ momen bending pada jarak $\mathrm{x}$, biasanya merupakan fungsi $\mathrm{x}$.

$\mathrm{C} 1$ dan $\mathrm{C} 2$ adalah konstanta integrasi sesuai bentuk batang

Regangan merupakan pertambahan panjang akibat beban yang diberikan ke arah aksial dari suatu batang pada konstruksi. Menghitung regangan dapat digunakan persamaan sebagai berikut : [3][4] :

$$
\varepsilon=\frac{\delta}{L}
$$

dimana :

$$
\begin{aligned}
& \varepsilon=\text { Regangan } \\
& \delta=\text { Perubahan bentuk aksial total }(\mathrm{mm}) \\
& \mathrm{L}=\text { panjang batang }(\mathrm{mm})
\end{aligned}
$$

Faktor keamanan merupakan angka yang dipakai untuk menentukan keamanan suatu rancangan konstruksi. Tegangan izin merupakan bagian kekuatan batas yang aman digunakan dalam perancangan. Faktor keamanan dapat dihitung dengan menggunakan persamaan berikut [1]:

$$
S F=\frac{\text { Fu }}{\mathrm{Fi}}
$$

Dimana : $\mathrm{SF}=$ faktor keamanan

$$
\begin{aligned}
& \mathrm{Fu}=\text { tegangan leleh/ultimit } \\
& \mathrm{Fi}=\text { tegangan ijin }
\end{aligned}
$$

\section{METODE}

Dalam penelitian ini mempergunakan peralatan sebagai berikut:

1. Perangkat komputer / Laptop

2. Software SolidWorks 19

3. Alat ukur (micrometer, meteran dan busur)

Model rangka seperti berikut :

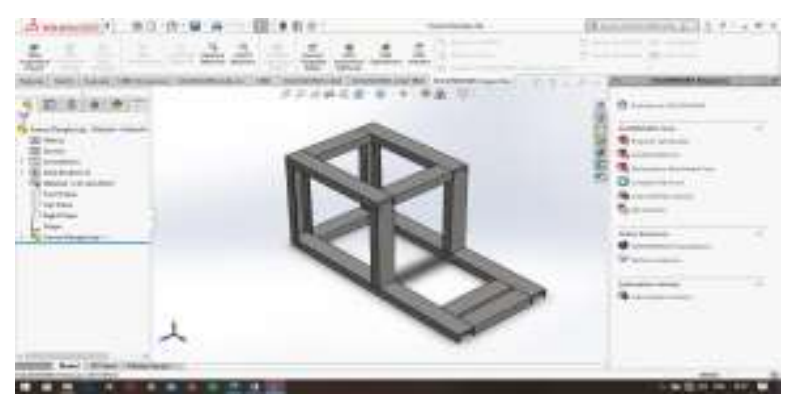

Gambar 1. Model Rangka 


\subsection{Langkah- langkah Proses Simulasi}
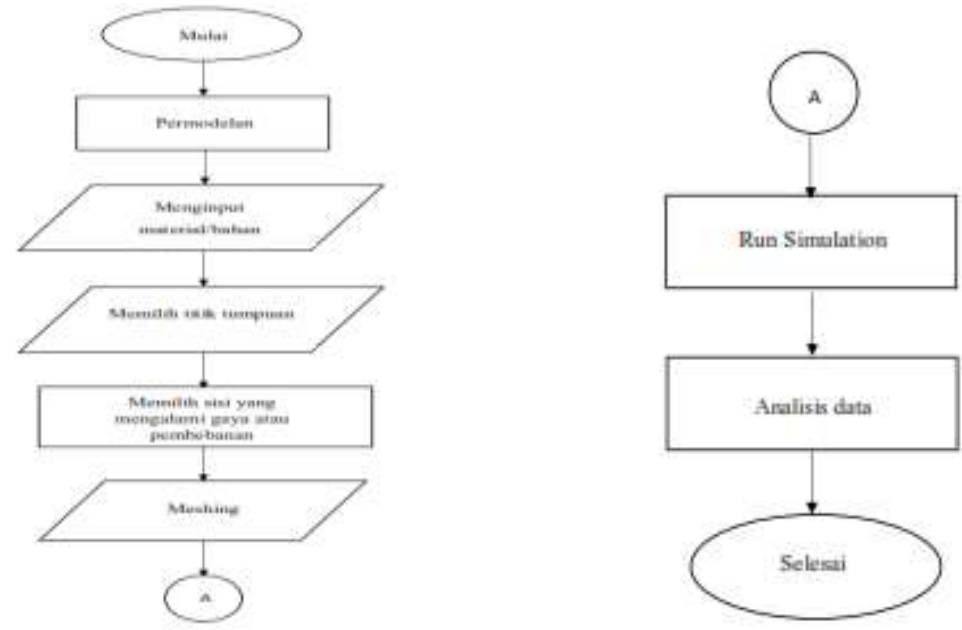

\subsection{Variasi Beban}

Gambar 2. Proses Simulasi

Tabel 3. Variasi Beban

\begin{tabular}{|c|c|}
\hline \multirow{2}{*}{ Beban } & $110 \mathrm{Kg}$ \\
\cline { 2 - 2 } & $4500 \mathrm{Kg}$ \\
\hline
\end{tabular}

\section{HASIL DAN PEMBAHASAN}

Simulasi yang dilakukan dengan perangkat lunak Solidworks 2019, diperoleh tegangan (Von Mises), perubahan bentuk (Displacement), regangan (Strain), dan faktor keamanan ( Safety Factor) dengan 2 variasi beban dan jenis material yang sama ditampilkan pada Gambar
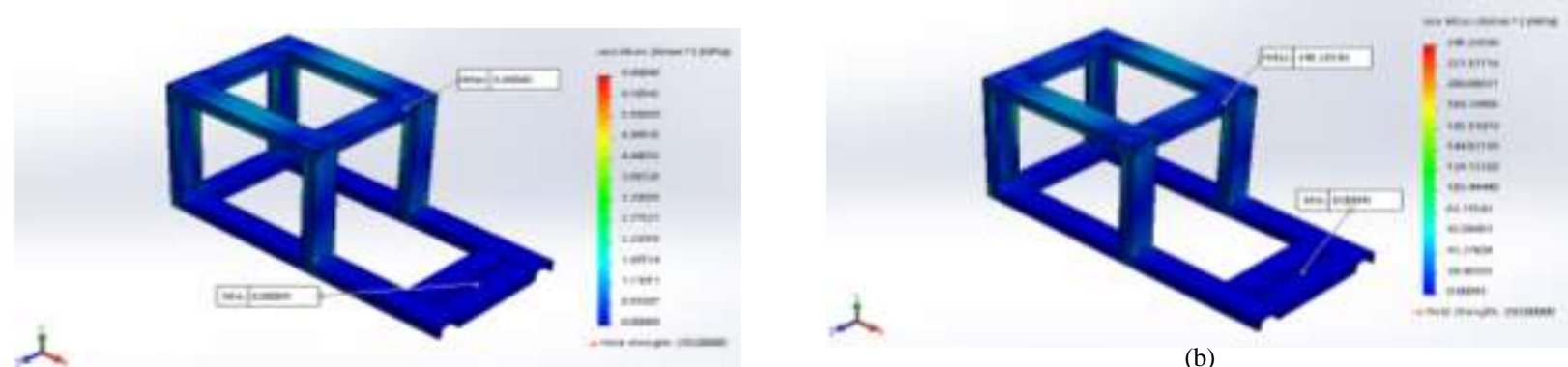

Gambar 3:Hasil simulasi Von Mises Stress dengan material Baja ASTM A36 (a) beban $110 \mathrm{Kg}$ dan

(b) beban $4500 \mathrm{Kg}$

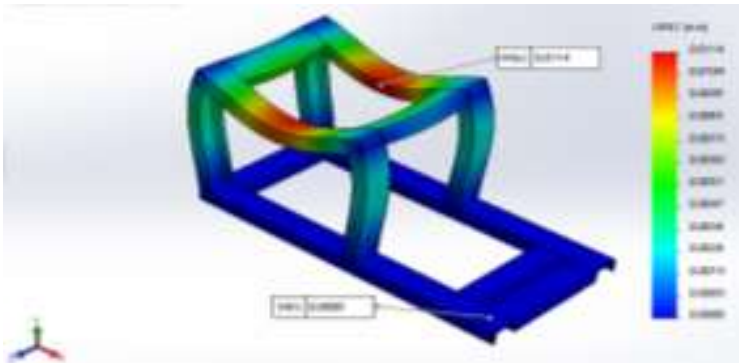

(a)

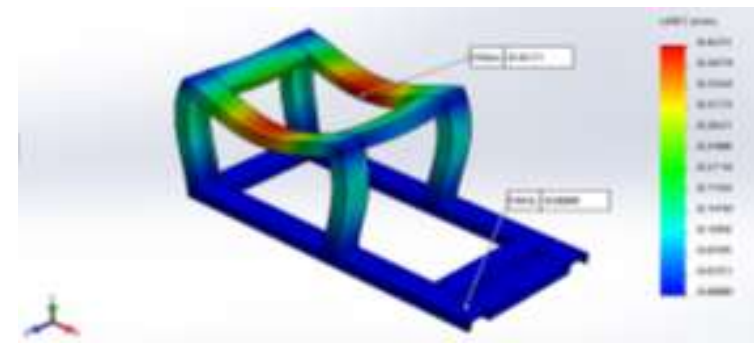

(b)

Gambar 4: Hasil simulasi Displacment dengan material Baja ASTM A36(a) beban $110 \mathrm{Kg}$ dan (b) beban $4500 \mathrm{Kg}$ 


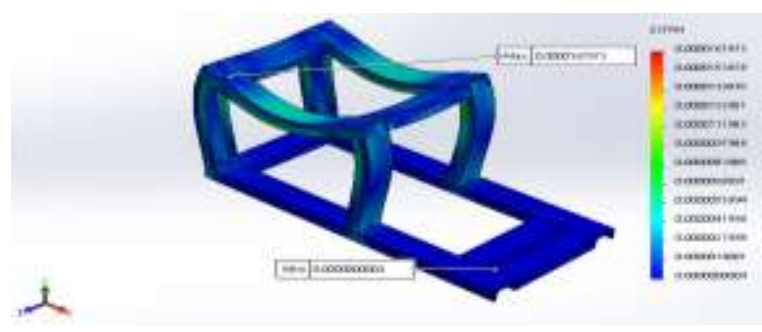

(a)

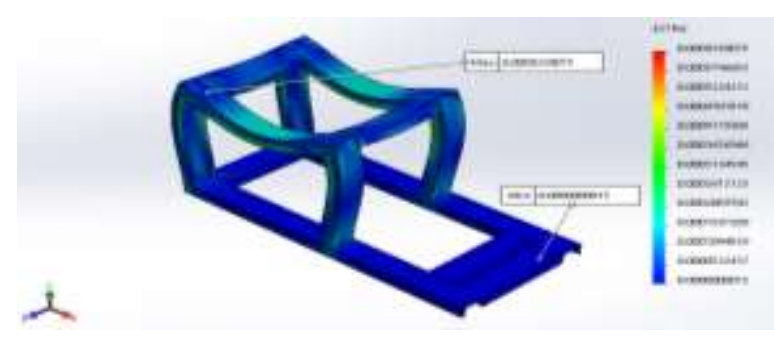

(b)

Gambar 5: Hasil simulasi Strain dengan material Baja ASTM A36(a) beban 110 Kg dan (b) beban $4500 \mathrm{Kg}$

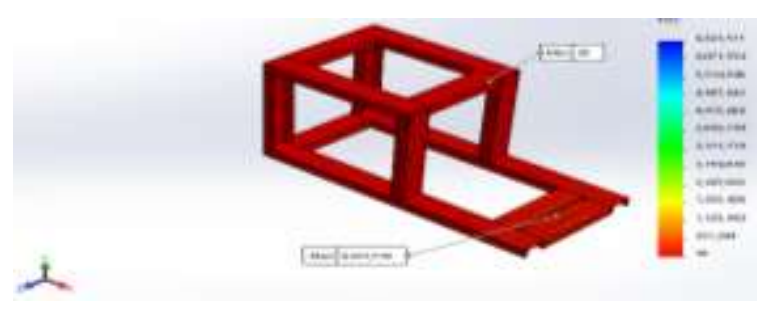

(a)

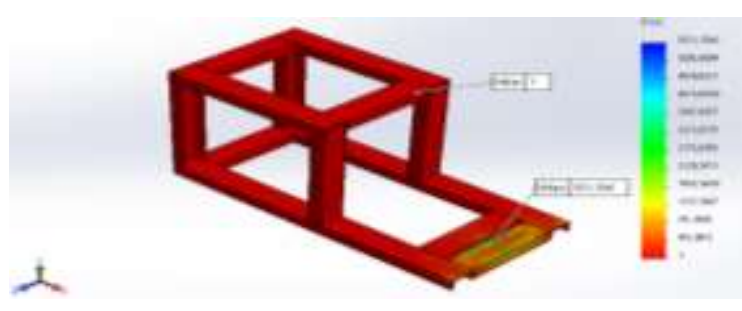

(b)

Gambar 6: Hasil simulasi Safety Factor dengan material Baja ASTM A36(a) beban $110 \mathrm{Kg}$ dan (b) beban $4500 \mathrm{Kg}$

Berdasarkan tabel hasil simulasi dengan 2 variasi beban yang berbeda yaitu $110 \mathrm{Kg}$ dan $4500 \mathrm{Kg}$, maka didapat nilai dari Von- mises Stress, Strain, Displacement, dan Safety Factor. adalah sebagai berikut ;

Tabel 4. Hasil simulasi

\begin{tabular}{|c|c|c|c|}
\hline \multirow{2}{*}{ Hasil Simulasi } & \multirow{2}{*}{ Keterangan } & \multicolumn{2}{|c|}{ Beban } \\
\cline { 2 - 4 } & & $110 \mathrm{kgf} / \mathrm{cm}^{\wedge} 2$ & $4500 \mathrm{kgf} / \mathrm{cm}^{\wedge} \mathbf{2}$ \\
\hline \multirow{2}{*}{ Von mises stress } & Minimum & 0.00004 & 0.00045 \\
\cline { 2 - 4 } & Maksimum & 6.66046 & 248.26596 \\
\hline \multirow{2}{*}{ Deformasi } & Minimum & 0 & 0 \\
\cline { 2 - 4 } & Maksimum & 0.0114 & 0.4231 \\
\hline \multirow{2}{*}{ Strain } & Minimum & 0.0000000004 & 0.0000000015 \\
\cline { 2 - 4 } & Maksimum & 0.0000167973 & 0.0006269075 \\
\hline \multirow{3}{*}{ Safety Factor } & Minimum & 38 & 1 \\
\cline { 2 - 4 } & Maksimum & 6.623 .511 & 551,786 \\
\hline
\end{tabular}

Gambar 3 menunjukkan tegangan yang terjadi pada rancangan yang dibuat cukup aman dimana nilai hasil simulasi dapat dilihat pada Tabel 4. Tegangan-regangan material pada rancangan dengan beban tangensial memberikan efek yang kecil pada suatu material dengan penampang yang berbentuk pipih [5]. Pembebanan yang diterima pada rangka Gambar 4 mengalami perubahan bentuk (deformasi) yang signifikan terkait besarnya beban yang diterima, hal ini terjadi karena masing-masing batang terhubung dalam sambungan yang bersifat kaku/rigid sehingga masing-masing batang mendapat tegangan tangensial. Kondisi ini dikuatkan dari jurnal terkait yang menyatakan bahwa tegangan tangensial pada batang yang terhubung memberikan perubahan bentuk yang signifikan terhadap beban yang diterima [6]. Faktor keamanan dari material ketika diberikan beban dimana konstruksinya masih aman, sesuai pada Gambar 6 dengan hasil seperti Tabel 4. Faktor keamanan material sangat 
dipengaruhi oleh tegangan dan modulus young dari material [7]. Nilai safety factor dapat dikatakan aman apabila mempunyai nilai minimal 1,25.

\section{Grafik hasil simulasi}

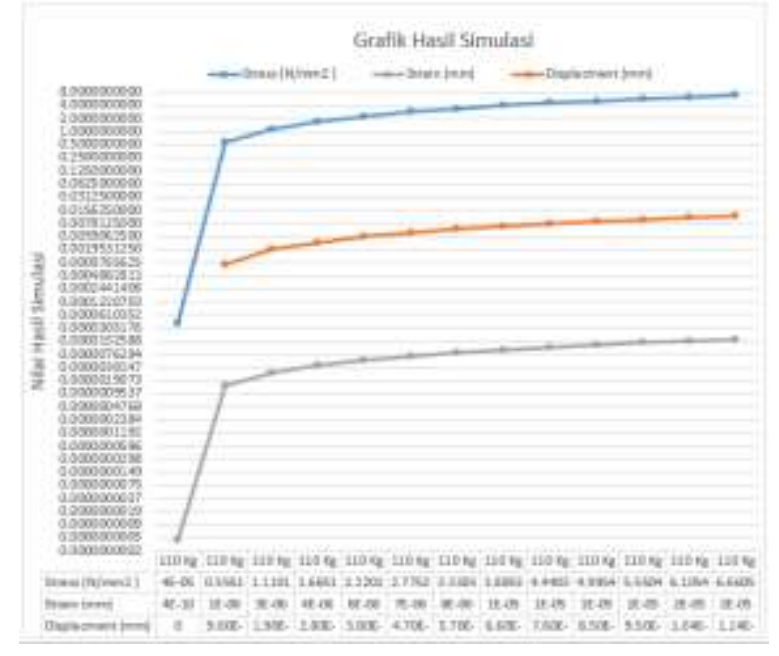

Gambar5. Hasil simulasi dengan beban $110 \mathrm{~kg}$

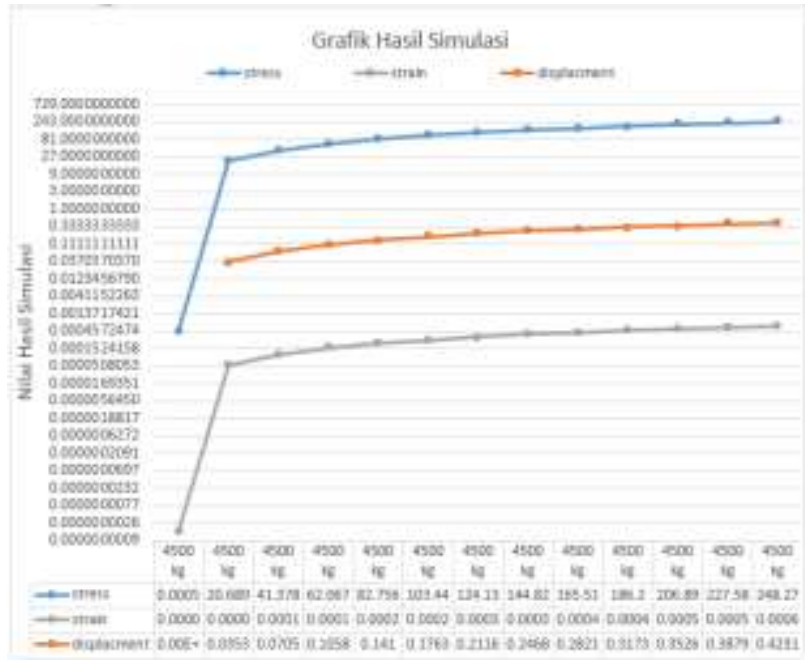

Gambar6. Hasil simulasi dengan beban $4500 \mathrm{~kg}$

\section{SIMPULAN}

Berdasarkan hasil analisa simulasi dari konstruksi rangka alat pembuat briket sampah organik dengan menggunakan perangkat lunak Solid Works 2019, didapatkan hasil simulasi terhadap Von- mises Stress, Strain, Displacement, dan Safety Factor, Sebagai berikut :

- Nilai Von Mises Stress maksimum yang terjadi saat dilakukan pembebanan $110 \mathrm{Kg}$ sebesar $6.66046 \mathrm{~N} / \mathrm{mm}^{2}(\mathrm{Mpa})$, Nilai displacement maksimum yang terjadi saat dilakukan pembebanan $110 \mathrm{Kg}$ sebesar0.0114 mm, Nilai Strain maksimum yang terjadi saat dilakukan pembebanan $110 \mathrm{Kg}$ sebesar $0.0000167973 \mathrm{~mm}$, dan Nilai Safety Factor minimal yang terjadi saat dilakukan pembebanan $110 \mathrm{Kg}$ sebesar 38 . Nilai tegangan yang dihasilkan dari pembebanan sebesar $110 \mathrm{Kg}$ masih dibawah batas maksimal kekuatan luluh material (yield strength) sebesar $250 \mathrm{Mpa}$.

- Nilai Von Mises Stress maksimum yang terjadi saat dilakukan pembebanan $4500 \mathrm{Kg}$ sebesar $248.26596 \mathrm{~N} / \mathrm{mm}^{2} \mathrm{Mpa}$ ), nilai displacement maksimum yang terjadi saat dilakukan pembebanan $4500 \mathrm{Kg}$ sebesar $0.4231 \mathrm{~mm}$. Regangan (Strain) maksimum yang terjadi saat dilakukan pembebanan $4500 \mathrm{Kg}$ sebesar $0.0006269075 \mathrm{~mm}$, dan nilai Safety Factor minimal yang terjadi saat dilakukan pembebanan $4500 \mathrm{Kg}$ sebesar1. Nilai tegangan maksimum yang dihasilkan dari pembebanan sebesar $4500 \mathrm{Kg}$ yang dilakukan sudah mendekati dari batas maksimal kekuatan luluh material (yield strength) rangka itu sendiri yang mempunyai kekuatan luluh $250 \mathrm{Mpa}$. Pembebanan sebesar $4500 \mathrm{~kg}$ pada rangka kurang aman untuk digunakan dan bersifat plastis.

\section{DAFTAR PUSTAKA}

[1] A. Jensen, H. H. Chenoweth, and D. Sebayang, Kekuatan Bahan Terapan. Erlangga, Jakarta, 1989.

[2] A. Joko, "Aplikasi Motode Elemen Hingga (MEH) pada Stuktur Rib Bodi Angkutan Publik," J. Inkuiri, vol. 1, no. 2, p. 10-15., 2010.

[3] L. D. M. Shigley, J. E., Perencanaan Teknik Mesin, 4th ed. Jakarta: Erlangga, 1984.

[4] Singer, Ferdinand L, Andrew Pytel, Kekuatan Bahan. Jakarta: Erlangga, 1985. 
[5] O. Ndubuaku, X. Liu, M. Martens, J. J. R. Cheng, and S. Adeeb, "The effect of material stress-strain characteristics on the ultimate stress and critical buckling strain of flat plates subjected to uniform axial compression," Constr. Build. Mater., vol. 182, pp. 346-359, 2018.

[6] S. Adibnazari and A. Anvari, "Frictional effect on stress and displacement fields in contact region," J. Mech. Eng. Res., vol. 9, no. 4, pp. 34-45, 2017.

[7] C. Maraveas, Y. C. Wang, and T. Swailes, "Reliability based determination of material partial safety factors for cast iron beams in jack arched construction exposed to standard and natural fires," Fire Saf. J., vol. 90, pp. 44-53, 2017. 